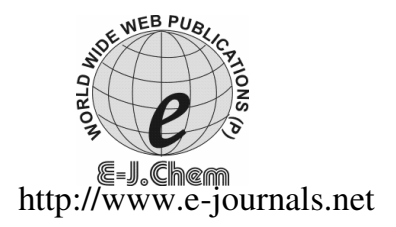

ISSN: 0973-4945; CODEN ECJHAO
E-Journal of Chemistry
2011, 8(4), 1784-1796

\title{
Spectrscopic and Conductometric Analysis of Gabapentin
}

\author{
SARA M. ANIS, MERVAT M. HOSNY*, \\ HISHAM E. ABDELLATEF and MOHAMED N. EL- BALKINY
}

Analytical Chemistry Department, Faculty of Pharmacy

Zagazig University, Zagazig, 44519, Egypt

mervat2200@yahoo.com

Received 11 December 2010; Revised 12 February 2011; Accepted 28 February 2011

\begin{abstract}
Four simple, sensitive and reproducible methods were developed for the determination of gabapentin (GPT) in pure form and in pharmaceutical preparations. Methods A and B are based on the reaction of cupric chloride with gabapentin to form stable complex, which could be measured spectrophotometrically at $\lambda_{\max } 246 \mathrm{~nm}$ (method A) or by using conductometric technique (method B). While method C and D depends on the formation of ion pair complex between the studied drug and bromothymol blue, bromocresol green respectively this was extractable with methylene chloride. The concentration ranges were $40-95 \mu \mathrm{g} \mathrm{mL} \mathrm{m}^{-1}, 1-15 \mathrm{mg}, 100-800$ and $10-150$ $\mu \mathrm{g} \mathrm{mL}^{-1}$ for methods A, B, C and D respectively .The optimization of various experimental conditions were described .The results obtained showed good recoveries, Ringbom optimum concentration ranges were calculated, in addition to molar absorptivity and sandell's sensitivity, detection and quantification limits. The methods were successfully applied to the determination of GPT in bulk and pharmaceutical preparations. The results were favorably comparable with the official method. The molar combining ratio for methods (A-B) was found to be (2:1) (drug: reagent) while for method (C-D) it was found to be $(1: 1)$.
\end{abstract}

Keywords: Cupric chloride, Bromothymol blue, Bromocresol green, Spectrophotometrically; Conductometric technique

\section{Introduction}

Gabapentin (1- (aminomethyl)cyclo-hexaneacetic acid) is a structural analogue of $g$-aminobutyric acid (GABA) (Scheme 1) and its action is attributed to the irreversible inhibition of the enzyme GABA-transaminase, thus preventing the physiological degradation of GABA in the brain; a secondary mechanism of a blockade for GABA uptake is also 
suggested $^{1}$, it is an antiepileptic effective in the treatment of partial seizures with or without secondary generalization and is used as adjunctive therapy in patients unresponsive to or intolerant of standard antiepileptic drugs ${ }^{2}$. A survey of the literature reveals that there were few reported methods for the determination of gabapentin using spectrophotometric technique $^{3-5}$, spectrofluorimetry ${ }^{6,7}$, capillary electrophoresis ${ }^{8}$, LC$\mathrm{MS}^{9}$ and HPLC ${ }^{10,11}$.

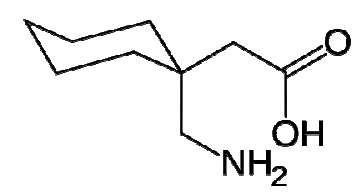

Scheme 1. Chemical structure of gabapentin

An inspection of both available methods for the cited drug reveals that only few spectrophotometric work were done, although conductometry is a rapid method and requires simple procedures, it has not been yet applied to the determination of gabapentin. The USP 30 described a liquid chromatographic method for its determination ${ }^{12}$.

The aim of this study was to apply simple, accurate, sensitive and reproducible reactions to analyze GPT in pure form and in pharmaceutical preparations, this study described methods that can be used in laboratories where modern and expensive equipment, such as that required for GC or HPLC is not available.

\section{Experimental}

Absorption spectra for all measurements were carried out using Shimadzu UV-260 double beam recording spectrometer with a $1 \mathrm{~cm}$ cell holder. All conductometric measurements were recorded using conductometer model CM-1K, Tokyo TOA electronics Ltd Japan. The $\mathrm{pH}$ values of solutions were measured using a Chemocadet $\mathrm{pH}$ meter.

\section{Materials and reagents}

Analytical grade reagents and double distilled water were used to prepare all solutions. GPT pure drug was obtained from Godecke AG, Germany under license of Park-Davis.Aqueous solutions of 1 and $4 \mathrm{mg} \mathrm{mL}^{-1}$ of GPT was prepared by dissolving 100 and $400 \mathrm{mg}$ of pure drug in $100 \mathrm{~mL}$ double distilled water respectively.

Stock solution of cupric chloride (Aldrich Chemical Co. Ltd) was prepared as $0.1 \%$ solution in double distilled water also $10^{-2} \mathrm{M}$ solution was prepared by dissolving 0.171 $\mathrm{g}$ in $100 \mathrm{~mL}$ double distilled water. Bromothymol blue sodium salt (BDH Chemicals Ltd., Poole, England) was prepared as $0.05 \%$ solution in double distilled water. Bromocresol green (Aldrich Chemical Co. Ltd) $0.025 \%$ solution was prepared by dissolving the weighed amount in $2.5 \mathrm{~mL} 0.1 \mathrm{M} \mathrm{NaOH}$ then completed to $100 \mathrm{~mL}$ using double distilled water ${ }^{13}$.

Borate buffer $\mathrm{pH} 7.5$ was used by dissolving $2.5 \mathrm{~g}$ of sodium chloride, $2.85 \mathrm{~g}$ of sodium tetraborate and $10.5 \mathrm{~g}$ of boric acid in sufficient water to produce $1000 \mathrm{~mL}$. Adjust the $\mathrm{pH}$ if necessary ${ }^{14}$. Also acetate buffer of $\mathrm{pH} 3.7$ was used by dissolving $10 \mathrm{~g}$ of anhydrous sodium acetate in $300 \mathrm{~mL}$ water, adjust to $\mathrm{pH} 3.7$ with glacial acetic acid and dilute to $1000 \mathrm{~mL}$ with water. If necessary, readjust to $\mathrm{pH} 3.7$ with glacial acetic acid or anhydrous sodium acetate as required, before use ${ }^{14}$.

Gaptin capsules (labeled to contain $100 \mathrm{mg}$ gabapentin per capsule) were obtained from Delta Pharma, Egypt. 


\section{Standard Drug Solutions}

The contents of ten capsules were emptied, pulverized. An accurately weighed amount equivalent to 100 and $400 \mathrm{mg}$ GPT were extracted by shaking with $50 \mathrm{~mL}$ distilled water, filtered, transferred to a $100 \mathrm{~mL}$ volumetric flask, completed to the mark using double distilled water. The general procedures were then followed using standard addition method.

\section{General procedures}

Spectrophotometric procedure using cupric chloride (method A)

Aliquots containing $0.4-0.95 \mathrm{mg}$ of gabapentin drug solution were transferred into $10 \mathrm{~mL}$ volumetric flasks, $1 \mathrm{~mL}$ of borate buffer $\mathrm{pH} 7.5$ was added, mixed then $2 \mathrm{~mL}$ of cupric chloride $0.1 \%$ solution was added, the volume was made up to $10 \mathrm{~mL}$ using distilled water, then the absorbance was measured at $246 \mathrm{~nm}$, against a reagent blank prepared according to the same treatment.

\section{Conductometric procedure (method B)}

Aliquot of sample solution containing 1-15 mg of drug were transferred to a $50 \mathrm{~mL}$ calibrated flask, volume was made up to the mark using bi-distilled water. The contents of the calibrated flask were transferred to a beaker and the conductivity cell was immersed. 10-2 M cupric chloride was used for titration, the conductance was measured subsequent to each addition of reagent solution and after thorough stirring for two min, corrected for dilution effect ${ }^{15}$, by means of the following equation, assuming that conductivity is a linear function of dilution.

$$
\Omega_{\text {correct }}^{-1}=\Omega_{\text {obs }}^{-1}\left[v_{l}+v_{2} / v_{l}\right]
$$

Where $\Omega^{-1}$ obs is the observed electrolytic conductivity, $v_{1}$ is the initial volume and $v_{2}$ is the volume of reagent added. A graph of corrected conductivity versus the volume of added titrant is constructed and the end-point is determined.

\section{Ion pair procedure using bromothymol blue (method C)}

Aliquots containing 1-8 mg of gabapentin drug solution were transferred into $125 \mathrm{~mL}$ separating funnels, $1.5 \mathrm{~mL}$ acetate buffer $\mathrm{pH} 3.7$ and $1.5 \mathrm{~mL} 0.05 \%$ bromothymol blue were added in order, mixed then the aqueous solution was extracted with an equal volume of methylene chloride and shaken for $30 \mathrm{sec}$, the mixture was allowed to separate into two phases. The organic layer was collected and dried over anhydrous sodium sulfate, completed to $10 \mathrm{~mL}$ with methylene chloride, the absorbance of the extract was measured at $411 \mathrm{~nm}$, against a reagent blank prepared according to the same treatment.

\section{Ion pair procedures using bromocresol green (method D)}

Aliquots containing 0.1-1.5 mg of gabapentin drug solution were transferred into $125 \mathrm{~mL}$ separating funnels and then treated with about $1.5 \mathrm{~mL}$ of acetate buffer $\mathrm{pH} 3.7,2.5 \mathrm{~mL}$ of $0.025 \%$ bromocresol green were then added and mixed, then the aqueous solution was extracted with an equal volume of methylene chloride and shaken for $30 \mathrm{sec}$, the mixture was allowed to separate into two phases. The organic layer was collected and dried with anhydrous sodium sulfate, completed to $10 \mathrm{~mL}$ with methylene chloride, the absorbance of the extracts was measured at $411 \mathrm{~nm}$, against a reagent blank prepared according to the same treatment

\section{Determination of the stoichiometry of the reaction}

In order to ascertain the stoichiometry of reaction Job's method of continuous variation ${ }^{16}$ was carried out using the same molarity of drug and reagent. 


\section{Results and Discussion}

\section{Spectrophotometric procedures using cupric chloride (method A)}

Binary complexes have been widely used in spectrophotometric analysis of many pharmaceutical compounds ${ }^{17-19}$. In this paper, the formed binary complex consists of the studied drug gabapentin and the metal ions, copper(II). This complex is water soluble with absorption maximum at $246 \mathrm{~nm}$, (Figure 1). The effects of the reagent concentrations, $\mathrm{pH}$ and temperature with respect to maximum sensitivity, adherence to beer's law and stability, have been studied through control experiments. The optimum conditions were established by varying one variable at a time and observing its effect on the absorbance of colored species ${ }^{20}$ :

- $2 \mathrm{~mL}$ of $0.1 \%$ cupric chloride solution was found to be satisfactory for maximum absorbance and was used throughout this investigation (Figure 2).

- $1 \mathrm{~mL}$ of borate buffer $\mathrm{pH} 7.5$ was needed to achieve best results (Figure 3).

- The reaction proceeded maximally at room temperature, no heating was required.

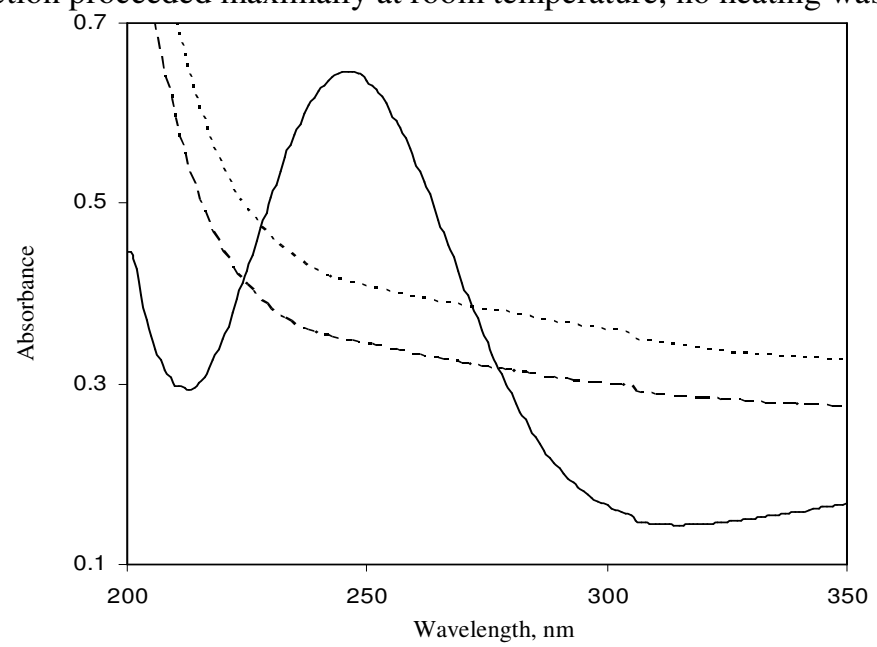

Figure 1. Absorption spectra of the complex formed through reaction of: $75 \mu \mathrm{g} \mathrm{mL}^{-1}$ gabapentin with cupric chloride in presence of borate buffer $\mathrm{pH} 7.5,75 \mu \mathrm{g} \mathrm{mL}^{-1}$ gabapentin with borate buffer $\mathrm{pH} 7.5$, cupric chloride with borate buffer $\mathrm{pH} 7.5$

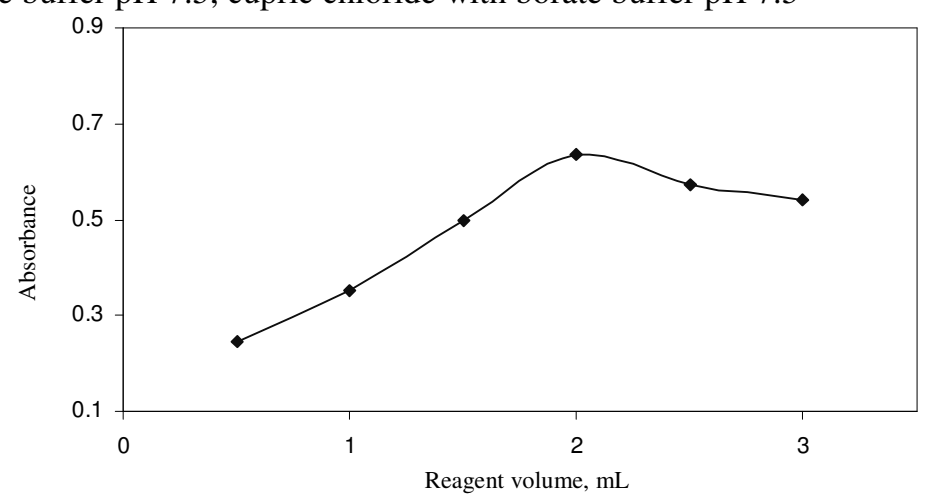

Figure 2. Effect of $0.1 \%$ cupric chloride volume on the reaction between cupric chloride and $75 \mu \mathrm{g} \mathrm{mL} \mathrm{L}^{-1}$ gabapentin 


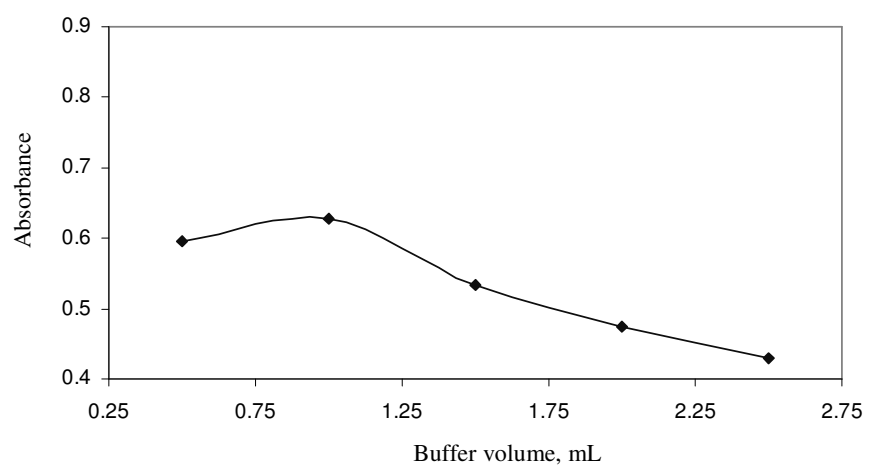

Figure 3. Effect of borate buffer $\mathrm{pH} 7.5$ volume on the reaction between cupric chloride and $75 \mu \mathrm{g} \mathrm{mL} \mathrm{g}^{-1}$ gabapentin

\section{Conductometric procedures using cupric chloride (method B)}

Conductometric analysis can be used in many titration procedures when ionic solutions are involved. As the conductance of a solution is related to the total ionic content, it can be applied to follow reactions that results in a change in this quantity. Conductance measurements are used successfully in quantitative titration of systems in which the conductance of the solution varies before and after the equivalence point. In these cases, the titration curve can be represented by two lines intersecting at the end point ${ }^{21-22}$.

Investigations were carried out to establish the most favorable conditions for the ion associates formation of gabapentin with cupric chloride to achieve sharp end point. The optimum conditions for performing the titration in a quantitative manner were elucidated as described below.

\section{Effect of solvent}

Seven different titrations were attempted:

(i) Aqueous drug solution with aqueous reagent solution,

(ii) Ethanol drug solution with ethanol reagent solution,

(iii) Drug solution with reagent solution, both in ethanol-water $(50 \%$, v/v) mixture

(iv) Methanol drug solution with methanol reagent solution,

(v) Drug solution with reagent solution, both in methanol-water $(50 \mathrm{v} / \mathrm{v})$ mixture

(vi) Acetone drug solution with acetone reagent solution and

(vii) Drug solution with reagent solution, both in acetone-water $(50 \% \mathrm{v} / \mathrm{v})$ mixture. Preliminary experiments showed that procedure in aqueous media was the most suitable for successful results, because in other procedures turbid solution was formed which caused some errors.

\section{Reagent's concentration}

Different concentrations of cupric chloride solution were tried ranging from $2.5 \times 10^{-3}$ to $2 \times 10^{-2}$ molar solution. The optimum concentration of the reagent was $10^{-2} \mathrm{M}$ in titration of the studied drug to achieve a constant and highly stable conductance reading within 1-2 min of mixing. Concentrations less or more than these limits showed only poor inflection at the end point.

Representative titration curve is shown in (Figure 4). Two straight lines are obtained, intersecting at the end-point, the first branch ascending the second one, conductance values slightly increase after the equivalence point. 


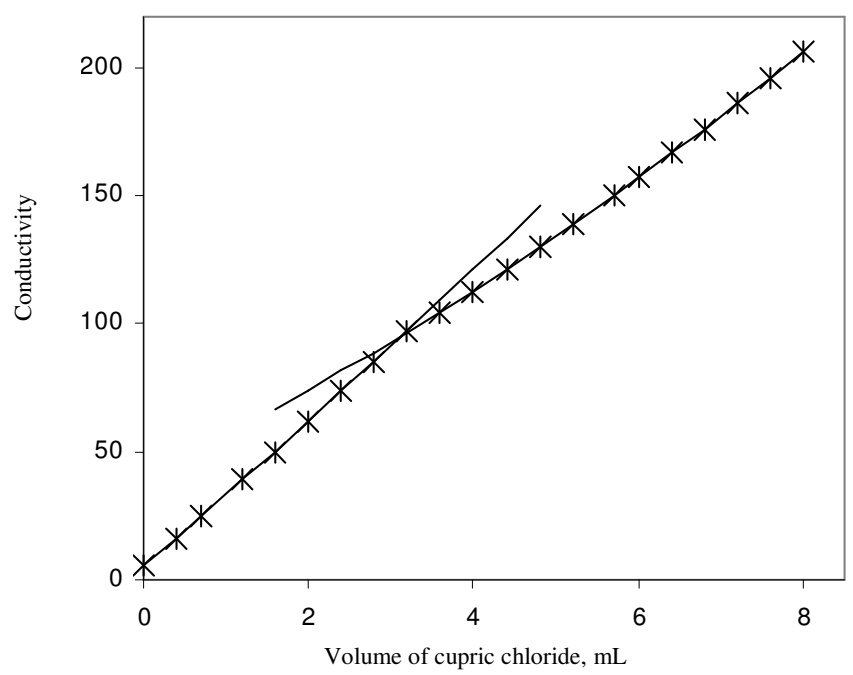

Figure 4. Conductometric titration curve of $11 \mathrm{mg}$ gabapentin $v s 10^{-2} \mathrm{M}$ cupric chloride

The conductance measured before the addition of the titrant (volume of $\mathrm{Cu}^{+2}$ equal zero) is related to the dissociation of the proton of the carboxylic group present in the gabapentin molecule. Up to the equivalence point, the titration involves the gradual substitution of the protons of the gabapentin molecule by cations of $\mathrm{Cu}^{+2}$. This increase of the conductance is because the mobility of the ion $\mathrm{H}^{+}$is larger than that of ion $\mathrm{Cu}^{+2}$, causing an increase in the slope of the conductometric curve (first branch of the curve). After the equivalence point, the measured conductance is the sum of the $\mathrm{Cu}^{+2}$ and $\mathrm{Cl}^{-}$present in the solution. As the sum of the mobilities of those ions is smaller than that of the $\mathrm{H}^{+}$cation, there is a decrease in the slope of the second section of the titration curve. The equivalence point is defined as the point of intersection of the two straight segments.

The conductometric titrations of different volumes of $10^{-2} \mathrm{M}$ cupric chloride solution were performed. The results show an obvious maximum in the conductance curve at drugreagent molar ratio of $(2: 1)$. The optimum concentration ranges for determination of gabapentin was in the range of $1-15 \mathrm{mg}$. At such range, distinct inflections and stable conductance reading were obtained.

\section{Ion pair procedures using bromothymol blue (method $C$ )}

The utility of bromothymol blue as ion-pairing reagent in assay of gabapentin was investigated here. The spectra of the reaction products show characteristic $\lambda_{\max }$ at $411 \mathrm{~nm}$ (Figure 5). The experimental conditions were established by varying one variable and observing its effect on the absorbance of the colored species as discussed below:

- $\quad 1.5 \mathrm{~mL}$ of $0.05 \%$ bromothymol blue was found to be sufficient for giving best results (Figure 6).

- Using different buffers of different $\mathrm{pH}$ in the range from (2-11), the intensity of the color of the formed complex increased when $1.5 \mathrm{~mL}$ of acetate buffer of $\mathrm{pH} 3.7$ was used (Figure 7).

- It was found that a single extraction of the ternary complex for 30 seconds was sufficient for complete extraction.

- Methylene chloride was found to be the most convenient solvent for the studied drug. 


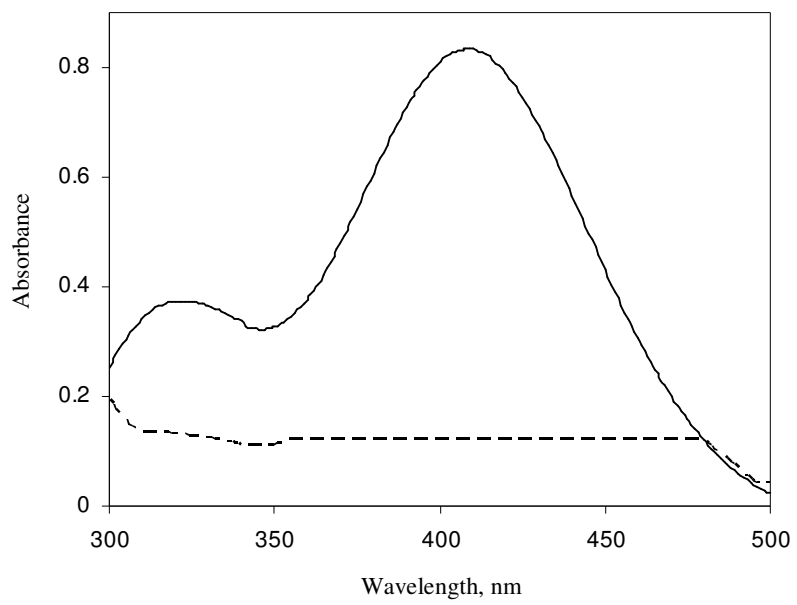

Figure 5. Absorption spectra of the ion pair formed through reaction of: $800 \mu \mathrm{g} \mathrm{mL}^{-1}$ gabapentin with $0.05 \%$ bromothymol blue blank solution

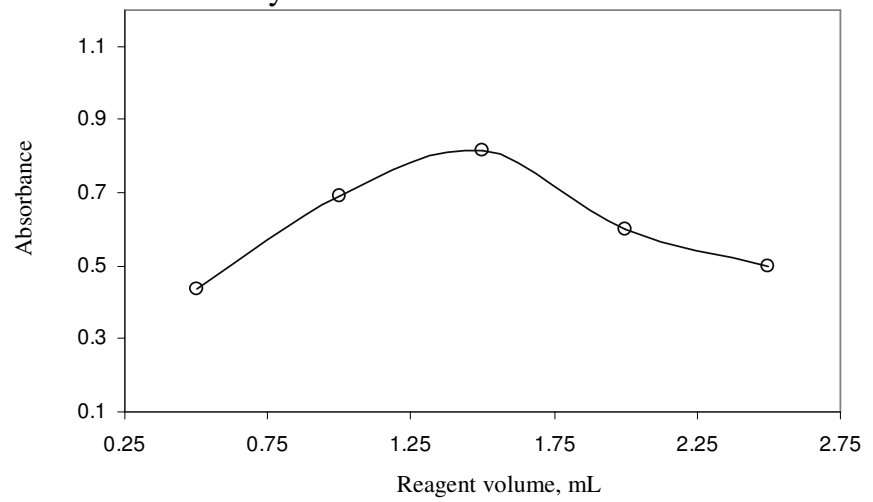

Figure 6. Effect of volume of $0.05 \%$ bromothymol blue on the reaction of bromothymol blue with $800 \mu \mathrm{g} \mathrm{mL}^{-1}$ gabapentin

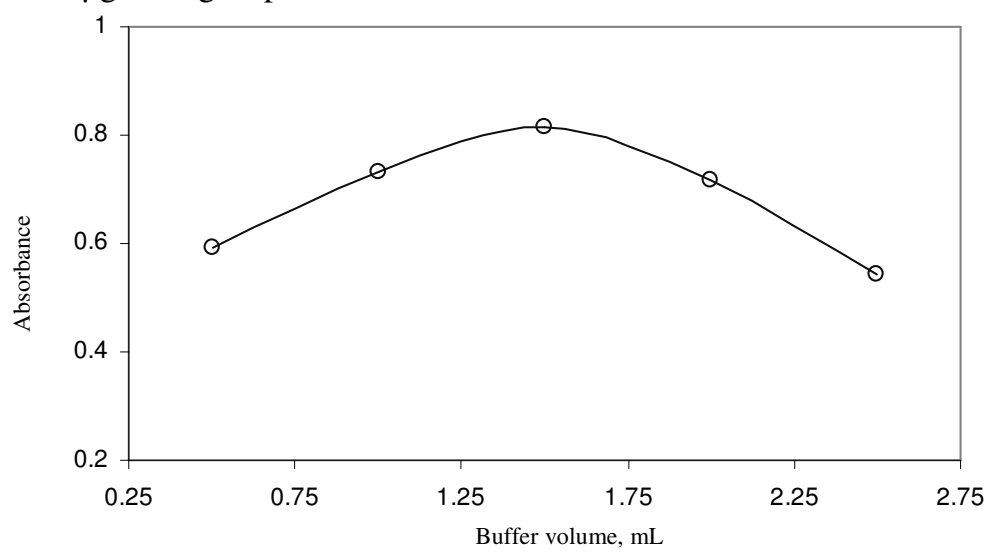

Figure 7. Effect of volume of acetate buffer $\mathrm{pH} 3.7$ on the reaction of bromothymol blue with $800 \mu \mathrm{g} \mathrm{mL}^{-1}$ gabapentin 


\section{Ion pair procedure using bromocresol green (method D)}

The utility of bromocresol green as ion-pairing reagent in assay of gabapentin was investigated here. The spectra of the reaction products show characteristic $\lambda_{\max }$ at $411 \mathrm{~nm}$ (Figure 8). The experimental conditions for the reaction between bromocresol green and gabapentin are discussed below:

- $2.5 \mathrm{~mL}$ of $0.025 \%$ bromocresol green was found to be sufficient to give maximum absorbance (Figure 9).

- Trying different buffer systems of different $\mathrm{pH}$ values, the intensity of the color of the formed complex increased when $1.5 \mathrm{~mL}$ of acetate buffer of $\mathrm{pH} 3.7$ was used (Figure 10).

- It was found that a single extraction of the ternary complex for 30 seconds was sufficient for complete extraction of the formed complex.

- Methylene chloride was found to be the most convenient solvent for the studied drug.

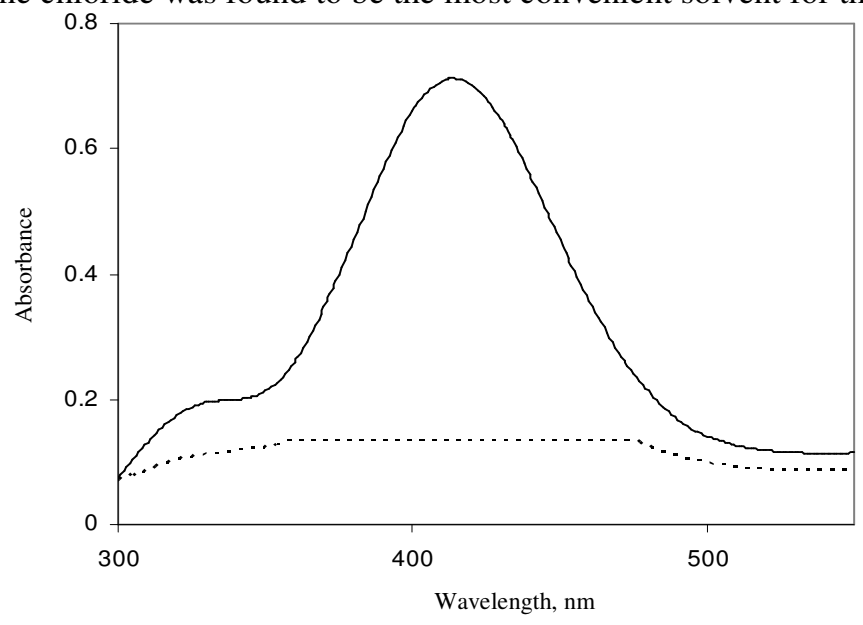

Figure 8. Absorption spectra of the ion pair formed through reaction of $100 \mu \mathrm{gLL}^{-1}$ gabapentin with $0.025 \%$ bromocresol green blank solution

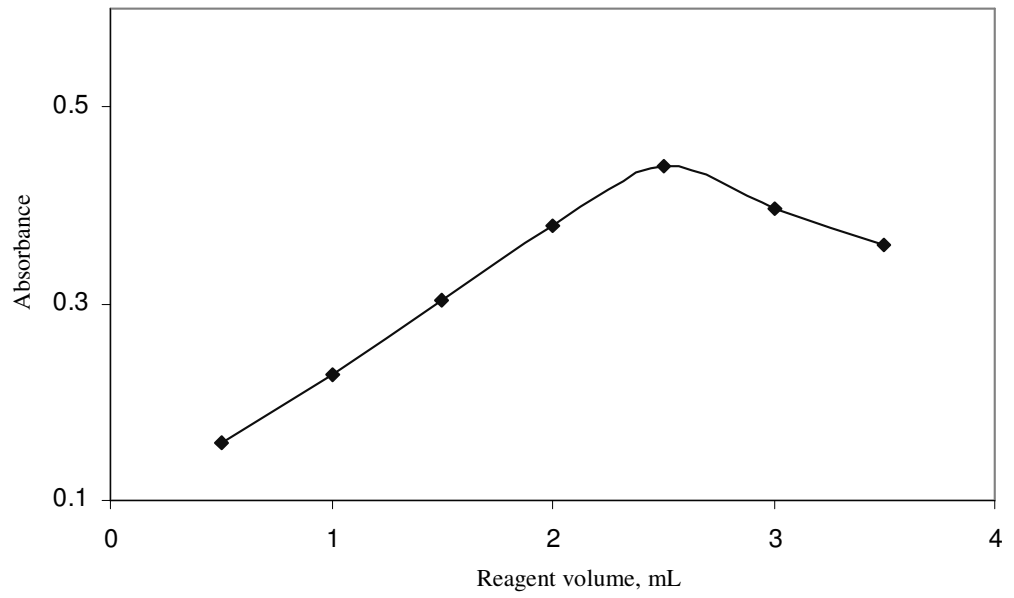

Figure 9. Effect of volume of $0.025 \%$ bromocresol green on the reaction of bromocresol green with $50 \mu \mathrm{g} \mathrm{mL}^{-1}$ gabapentin 


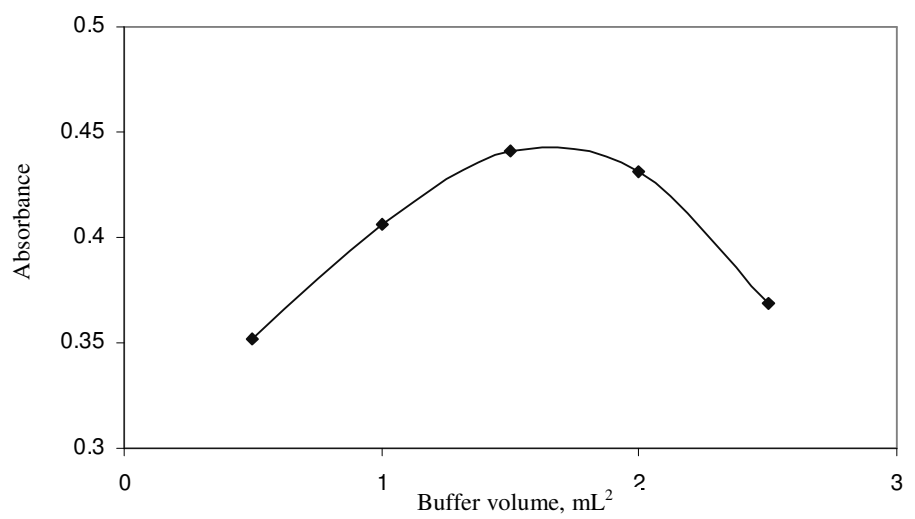

Figure 10. Effect of acetate buffer $\mathrm{pH} 3.7$ volume on the reaction of bromocresol green with $50 \mu \mathrm{g} \mathrm{mL}^{-1}$ gabapentin

\section{Stoichiometric relationship}

Using Job's method of continuous variation, the molar ratio of gabapentin to cupric chloride was found to be 2:1, while for bromothymol blue and bromocresol green it was found to be 1:1 (Figure 11-13). The mechanisms of the methods are suggested in Scheme 2.

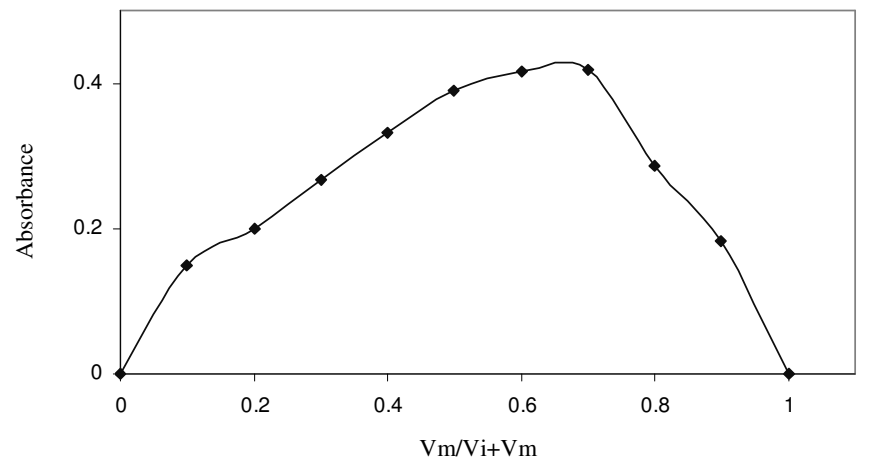

Figure 11. Determination of the stoichiometry of the reaction of: Gabapentin $\left(5 \times 10^{-3} \mathrm{M}\right)$ and cupric chloride $\left(5 \times 10^{-3} \mathrm{M}\right)$

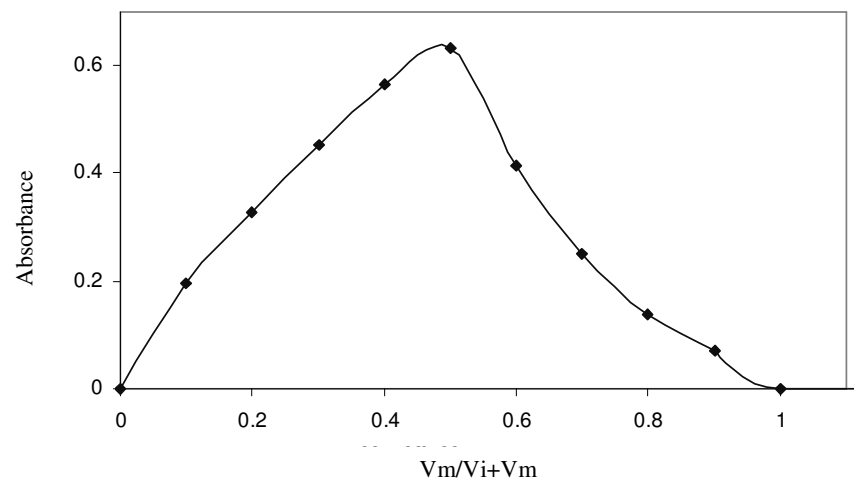

Figure 12. Determination of the stoichiometry of the reaction of: Gabapentin $\left(1.25 \times 10^{-3} \mathrm{M}\right)$ and bromothymol blue $\left(1.25 \times 10^{-3} \mathrm{M}\right)$ 


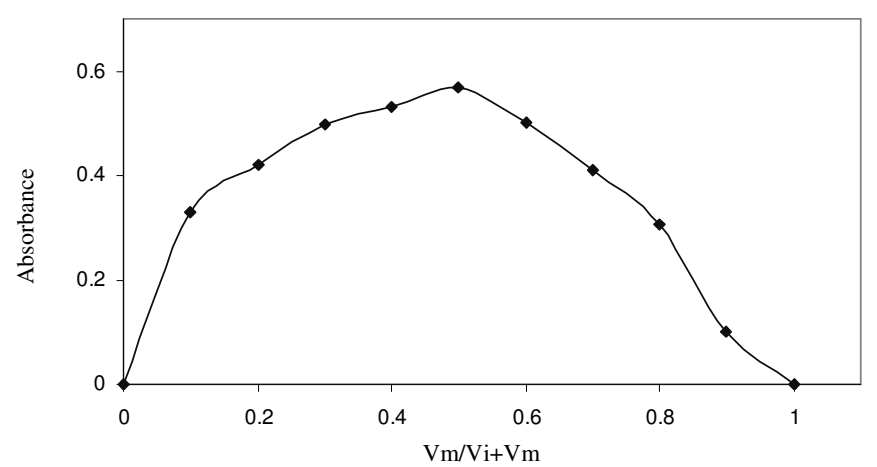

Figure 13. Determination of the stoichiometry of the reaction of gabapentin $\left(1.25 \times 10^{-3} \mathrm{M}\right)$ and bromocresol green $\left(1.25 \times 10^{-3} \mathrm{M}\right)$

A)<smiles>NCC(CCCCCCl)(CC(=O)O)CC(Cl)Cl</smiles>

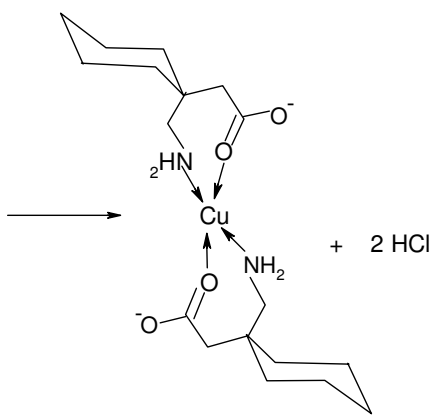

B)

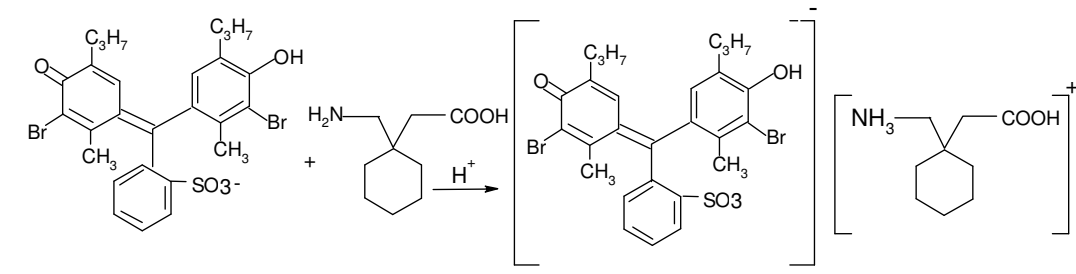

C)<smiles>CC1=C(Br)C(=O)C(Br)=CC1=C(c1ccccc1[Se])c1cc(Br)c(O)c(Br)c1C</smiles>

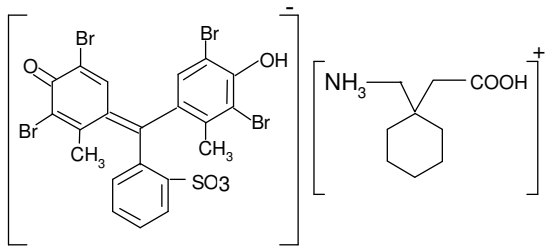

Scheme 2. Proposed reactions of gabapentin with A) Cupric chloride B) Bromothymol blue C) Bromocresol Green

\section{Methods of validation}

The developed analytical methods were validated as per ICH (The International Conference on Harmonisation of Technical Requirements for Registration of Pharmaceuticals for Human Use), guideline and USP (United States Pharmacopeia) requirement ${ }^{23-24}$, applying a pharmaceutical preparation analysis. Under the described experimental conditions, calibration graphs were constructed for all of the studied methods, as can be seen from (Table 1), linear relationship was found between the absorbance at $\lambda_{\max }$ and the concentration 
of the drug in the ranges of $40-95 \mu \mathrm{g} \mathrm{mL}^{-1}, 100-800$ and $10-150 \mu \mathrm{g} \mathrm{mL} \mathrm{L}^{-1}$ for methods $\mathrm{A}$, $\mathrm{C}$ and $\mathrm{D}$ respectively. It was observed that method $\mathrm{D}$ is the most sensitive one. The values of beer's law limits, ringbom concentrations ranges, regression equations, correlation coefficients, molar absorptivity, sandell's sensitivety, limit of detection (LOD) and limit of quantification (LOQ) for each method were all summarized in (Table 1). The optimum concentration ranges of gabapentin that can be measured accurately as evaluated from the Ringbom plot were 56.2-85.11, 199.5-707.9, 19.95- 85.11 $\mu \mathrm{g} \mathrm{mL}^{-1}$ for methods A, C and $\mathrm{D}$ respectively. The standard deviations, relative standard deviations, standard errors, variances were all listed in (Table 2), the average percent recoveries as can be seen from the same table indicates good accuracy of the methods.

Table 1. Spectral characteristics and statistical data of the regression equations for the product formed through reactions (A, C and D)

\begin{tabular}{lccc}
\hline Parameters & Method A & Method C & Method D \\
\hline Linearity range, $\mu \mathrm{g} \mathrm{mL}^{-1}$ & $40-95$ & $100-800$ & $10-150$ \\
Ringbom range, $\mu \mathrm{g} \mathrm{mL}^{-1}$ & $56.2-85.11$ & $199.5-707.9$ & $19.95-85.11$ \\
Molar absorptivity $\mathrm{mol}^{-1} \mathrm{~cm}^{-1}$ & $1.33 \times 10^{3}$ & $1.99 \times 10^{2}$ & $1.54 \times 10^{3}$ \\
Sandell's sensitivity, $\mu \mathrm{g} \mathrm{mL}^{-1}$ per 0.001 A & $7.76 \times 10^{-4}$ & $1.17 \times 10^{-4}$ & $8.98 \times 10^{-4}$ \\
Regression equation : & & & \\
Intercept (a) & -0.549 & 0.076 & 0.175 \\
Slope (b) & 0.016 & 0.00092 & 0.0053 \\
Correlation coefficient (r) & 0.9995 & 0.9998 & 0.9999 \\
Variance & 1.09 & 1.38 & 1.71 \\
Limit of detection LOD, $\mu \mathrm{g} \mathrm{mL}{ }^{-1}$ & 1.179 & 1.44 & 1.61 \\
Limit of quantitation LOQ, $\mu \mathrm{g} \mathrm{mL}^{-1}$ & 3.89 & 4.75 & 5.30 \\
\hline
\end{tabular}

* calculated on the basis of the molecular weight of the drug

Table 2. Determination of gabapentin by using methods (A-D)

\begin{tabular}{|c|c|c|c|c|c|c|c|c|c|c|c|}
\hline \multicolumn{3}{|c|}{ Method A } & \multicolumn{3}{|c|}{ Method B } & \multicolumn{3}{|c|}{ Method C } & \multicolumn{3}{|c|}{ Method D } \\
\hline 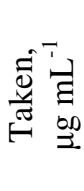 & 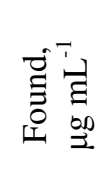 & $\begin{array}{l}0 \\
0 \\
\overrightarrow{0} \\
2 \\
0 \\
0 \\
0 \\
0\end{array}$ & 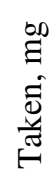 & 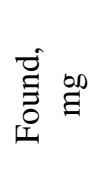 & $\begin{array}{l}0 \\
2 \\
\overrightarrow{0} \\
0 \\
0 \\
0 \\
0\end{array}$ & 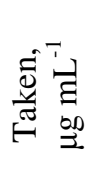 & 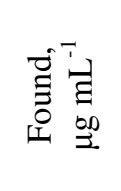 & 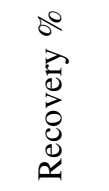 & 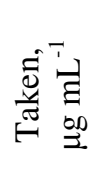 & 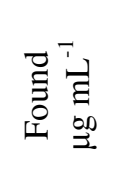 & $\begin{array}{l}0^{\circ} \\
\overrightarrow{0} \\
0 \\
0 \\
0 \\
0 \\
0\end{array}$ \\
\hline 40 & 40.25 & 100.6 & 1 & 0.99 & 99.31 & 100 & 98.91 & 98.91 & 10 & 9.81 & 98.11 \\
\hline 50 & 49.00 & 3 & 3 & 3.01 & 100.47 & 200 & 201.09 & 100.54 & 25 & 24.91 & 99.62 \\
\hline 60 & 58.88 & 98.00 & 5 & 5.00 & 100.00 & 300 & 303.26 & 101.09 & 50 & 50.00 & 100.00 \\
\hline 75 & 74.69 & 98.13 & 7 & 7.02 & 100.29 & 400 & 405.43 & 101.36 & 75 & 76.42 & 101.89 \\
\hline 85 & 83.13 & 99.58 & 9 & 8.99 & 99.89 & 500 & 492.39 & 98.48 & 100 & 101.13 & 101.13 \\
\hline 90 & 89.25 & 97.79 & 11 & 10.96 & 99.63 & 800 & 803.26 & 100.41 & 150 & 149.62 & 99.75 \\
\hline 95 & 94.56 & 99.17 & 13 & 13.01 & 100.08 & & & & & & \\
\hline & & 99.54 & 15 & 15.07 & 100.47 & & & & & & \\
\hline \multicolumn{3}{|c|}{$\begin{array}{l}\text { Mean* } 98.98 \\
(p=0.05)\end{array}$} & & \multicolumn{2}{|c|}{100.02} & \multicolumn{3}{|c|}{100.13} & \multicolumn{3}{|c|}{100.08} \\
\hline & \multicolumn{2}{|l|}{7} & \multirow{2}{*}{\multicolumn{2}{|c|}{8}} & \multicolumn{3}{|c|}{6} & \multicolumn{3}{|c|}{6} \\
\hline & & \multirow{2}{*}{$\begin{array}{l}1.04 \\
1.05\end{array}$} & \multirow{2}{*}{\multicolumn{3}{|c|}{$\begin{array}{l}0.405 \\
0.404\end{array}$}} & \multirow{2}{*}{\multicolumn{3}{|c|}{$\begin{array}{l}1.173 \\
1.172\end{array}$}} & \multicolumn{3}{|c|}{1.309} \\
\hline \multicolumn{2}{|c|}{ R.S.D. } & & & & & & & & \multirow{2}{*}{\multicolumn{3}{|c|}{$\begin{array}{c}1.308 \\
1.71\end{array}$}} \\
\hline \multicolumn{2}{|c|}{$\mathrm{V}$} & 1.09 & \multicolumn{3}{|c|}{0.164} & \multicolumn{3}{|c|}{1.38} & & & \\
\hline \multicolumn{2}{|l|}{ S.E. } & 0.394 & \multicolumn{3}{|c|}{0.143} & \multicolumn{3}{|c|}{0.479} & \multicolumn{3}{|c|}{0.534} \\
\hline
\end{tabular}


The proposed methods were applied for determination of the selected drug in its capsule form (Table 3). Experiments showed that there was no interference from the additives e.g. lactose, fructose, magnesium stearate and starch. The methods performance was assessed using the t-test (for accuracy) and a variance ratio $F$-values, both values did not exceed the theoretical values (95\% confidence limit), so we concluded that the proposed methods do not differ significantly from the official one, (Table 4).

Table 3. Determination of gaptin capsule by using methods (A-D)

\begin{tabular}{|c|c|c|c|c|c|c|c|c|c|c|c|}
\hline \multicolumn{3}{|c|}{ Method A } & \multicolumn{3}{|c|}{ Method B } & \multicolumn{3}{|c|}{ Method C } & \multicolumn{3}{|c|}{ Method D } \\
\hline 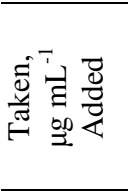 & 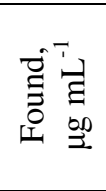 & $\begin{array}{l}0 \\
0 \\
2 \\
0 \\
0 \\
0 \\
0 \\
0 \\
01\end{array}$ & 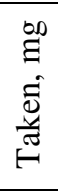 & $\begin{array}{l}00 \\
\Xi \\
\dot{\Xi} \\
\Xi \\
0 \\
0\end{array}$ & 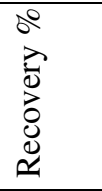 & 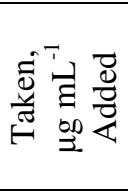 & 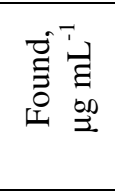 & 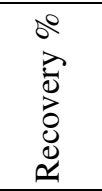 & 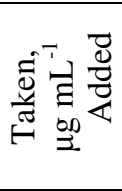 & 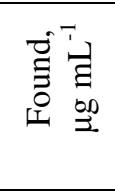 & 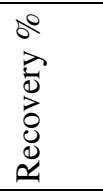 \\
\hline 40 & 40.56 & 101.41 & 2 & 1.99 & 99.30 & 100 & 101.09 & 101.09 & 10 & 9.62 & 96.23 \\
\hline 40 & 40.69 & 101.72 & 4 & 4.01 & 100.18 & 400 & 395.65 & 98.91 & 10 & 10.19 & 101.89 \\
\hline 60 & 59.44 & 99.06 & 8 & 8.01 & 100.13 & 500 & 493.48 & 98.70 & 20 & 20.38 & 101.89 \\
\hline 65 & 66.19 & 101.83 & 10 & 10.10 & 101.03 & 600 & 590.22 & 98.37 & 25 & 25.28 & 101.13 \\
\hline 70 & 70.56 & 100.80 & & & & 700 & 680.43 & 97.20 & 30 & 30.38 & 101.26 \\
\hline 80 & 79.94 & 99.92 & & & & 800 & 798.91 & 99.86 & 100 & 100.75 & 100.75 \\
\hline $\begin{array}{c}\text { Mean }^{*} \\
(p=0.05\end{array}$ & & 100.67 & & 100.1 & & & 98.61 & & & 101.38 & \\
\hline $\mathrm{N}$ & & 5 & & 4 & & & 5 & & & 5 & \\
\hline S.D. & & 1.18 & & 0.70 & & & 0.962 & & & 0.495 & \\
\hline V & & 1.39 & & 0.49 & & & 0.926 & & & 0.245 & \\
\hline S.E. & & 0.529 & & 0.35 & & & 0.430 & & & 0.221 & \\
\hline
\end{tabular}

Table 4. Statistical data for the determination gabapentin using method (A-D) compared with reference method ${ }^{4}$.

\begin{tabular}{cccccc}
\hline Parameters & $\begin{array}{c}\text { Reference } \\
\text { method }\end{array}$ & Method A & Method B & Method C & Method D \\
\hline Mean & 99.59 & 98.98 & 100.02 & 100.13 & 100.08 \\
$(\mathrm{p}=0.05)$ & 5 & 7 & 8 & 6 & 6 \\
N & 5 & 1.04 & 0.405 & 1.173 & 1.309 \\
S.D. & 0.650 & 1.05 & 0.404 & 1.172 & 1.308 \\
R.S.D & 0.653 & 1.09 & 0.164 & 1.38 & 1.71 \\
V & 0.423 & $1.15(2.228)^{*}$ & $1.48(2.201)^{*}$ & $0.913(2.262)^{*}$ & $0.758(2.262)^{*}$ \\
t & - & $2.58(4.53)^{*}$ & $2.58(4.12)^{*}$ & $3.26(5.19)^{*}$ & $4.04(5.19)^{*}$ \\
F & - & Theoretical values of t and F at $p=0.05$ &
\end{tabular}

\section{Conclusion}

The data given above reveals that the proposed methods introduce new techniques for the determination of gabapentin. The studied methods showed the advantage of being simple, accurate and sensitive with good precision and accuracy. Using of bromocresol green allowed the detection of gabapentin in small amount of $10 \mu \mathrm{g} \mathrm{mL}^{-1}$. With these methods, one can do the analysis in a short time at low cost without losing accuracy. The proposed methods can be used as alternative methods to reported ones for the routine determination of gabapentin in the pure form and in pharmaceutical formulations. 


\section{References}

1. Ouellet D, Bockbrader H N, Wesche D L, Shapiro D Y and Garofalo E, Epilepsy Res., 2001, 47(3), 229-241.

2. Sweetman S C, Martindale the Complete Drug Reference, $35^{\text {th }}$ Ed., Pharmaceutical Press: London, 2007, 437.

3. Abdellatef H E and Khalil H M, J Pharm Biomed Anal., 2003, 31(1), 209-214.

4. Farhan A, Siddiqui, Saeed M A, Najma S, Faiza Q, Agha Z M, Hashim Z M, Saima S B, Nawab S A and Hina S and Nadia R, Eur J Med Chem., 2010, 45(7), 2761-2767.

5. Al-Zehouri J, Al-Madi S and Belal F, Arzneimittel-Forschung., 2001, 51, 97-103.

6. Belal F, Abdine H, Al-Majed A and Khalil N Y, J Pharm Biomed Anal., 2002, 27, 253-260.

7. Hassan E M, Belal F, Al-Deeb O A and Khalil N Y, J AOAC Int., 2001, 84, 1017-1024.

8. $\quad$ Sekar R and Azhaguvel S, J Pharm Biomed Anal., 2004, 36(3), 663-667.

9. Ojha A, Rathod R, Patel C and Padh H, Chromatogr., 2007, 66, 853-857.

10. Jalalizadeh H, Souri E, Tehrani M B and Jahangiri A, J Chromatogr B., 2007, 854, 43-47.

11. Laura M, Roberto M, Mario A and Maria A R, J Pharm Biomed Anal., 2010, 53(1), 62-97.

12. United States Pharmacopeia 30, the national formulary, the United States pharmacopeial convention, Mack, Easton, 2007.

13. Tipparat P, Lapanantnoppakhun S, Jakmunee J and Grudpan K, J Pharm Biomed Anal., 2002, 30(1), 105-112.

14. British Pharmacopoeia, Stationary office, London, 2007, A136.

15. Lingane J, Electroanal Chemstry., $2^{\text {nd }}$ Ed., Interscience: New York, 1958, 90.

16. Rose J, Advanced Physio-Chemical Experiments, Pitman: London, 1964, 54.

17. El-Ragehy N A, Abdelkawy M and El-Bayoumy A, Anal Lett., 1994, 27, 2127.

18. Minic D, Petkovic J, Koricanac Z and Jovanovic T, J Pharm Biomed Anal., 1996, 14(8-10), 1355-1358.

19. EL-Sherif Z A, J Anal Lett., 1999, 32, 65-78.

20. Massart D L, Vandeginste B G M, Deming S N, Michtte Y and Kaufmann L, Chemometries Elsevier, A Textbook, Amsterdam, 1988, 390-393.

21. Rizk M S, Belal F and Eid M M, J Acta Pharm Hung., 1993, 63(6), 313-318.

22. Altiokka G, Can N O and Aboul-Enein H Y, J Liquid Chromatogr Relat Technol., 2007, 30, 1333.

23. The European Agency for the Evaluation of Medicinal Products, ICH Topic Q 2B Note for Guideline on Validation of Analytical Procedures, Methodology GPMP/ICH/281/95, 1996.

24. United States Pharmacopoeia, Validation of Compendial Methods, $26^{\text {th }}$ Ed., Pharmacopoeial Convention Inc.: Rock-Ville, MD, 2003, 2439-2442. 


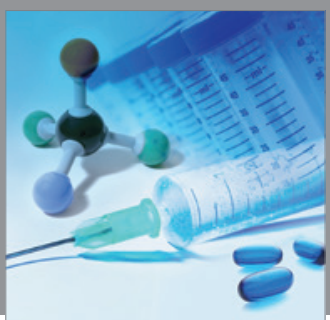

International Journal of

Medicinal Chemistry

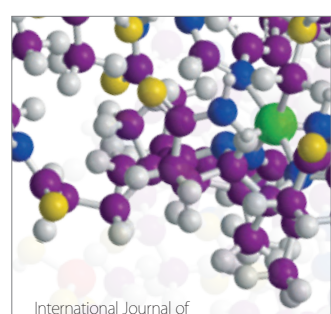

Carbohydrate Chemistry

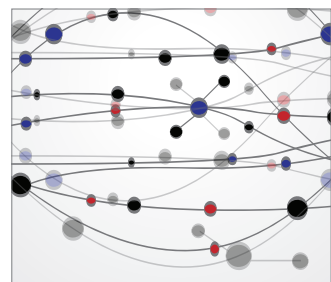

The Scientific World Journal
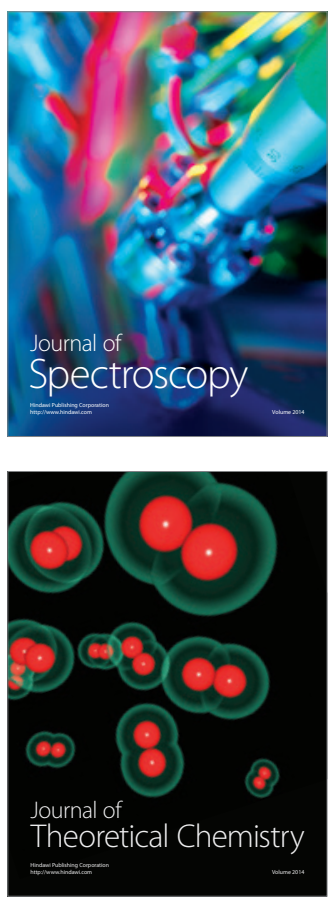
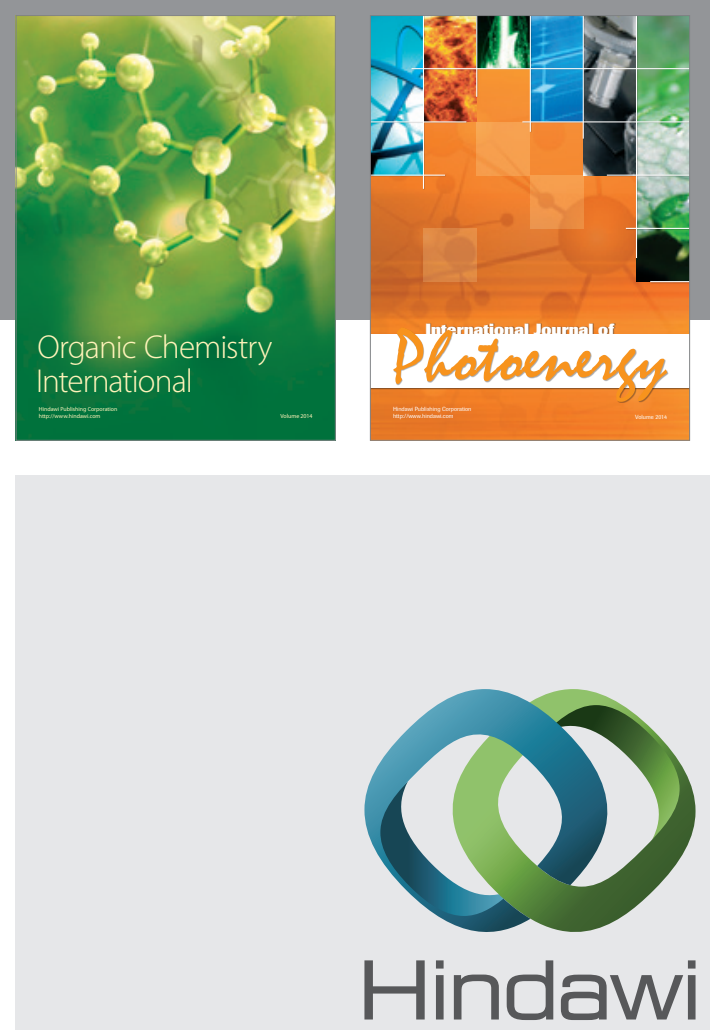

Submit your manuscripts at

http://www.hindawi.com
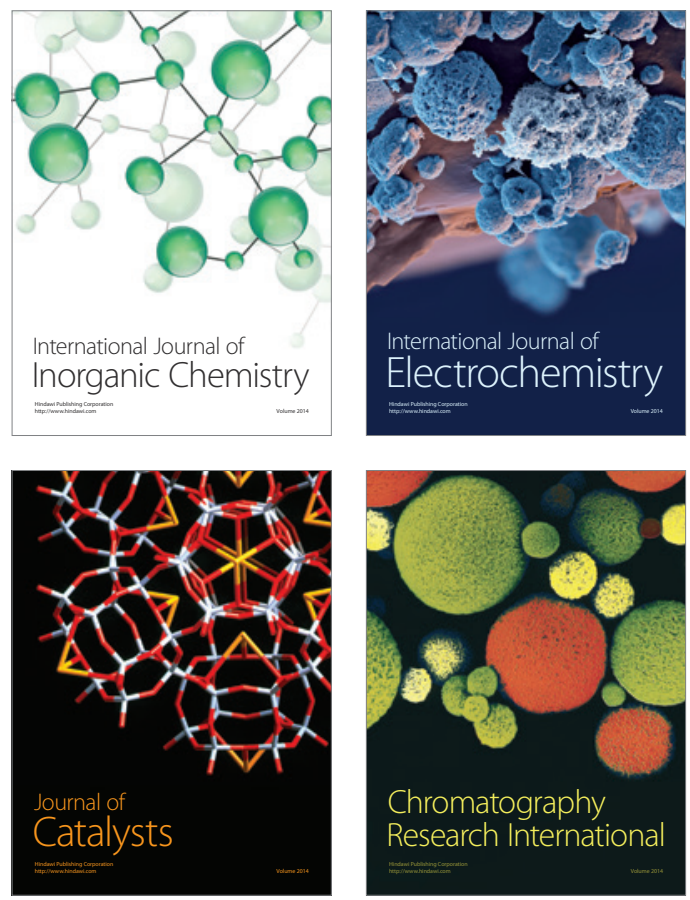
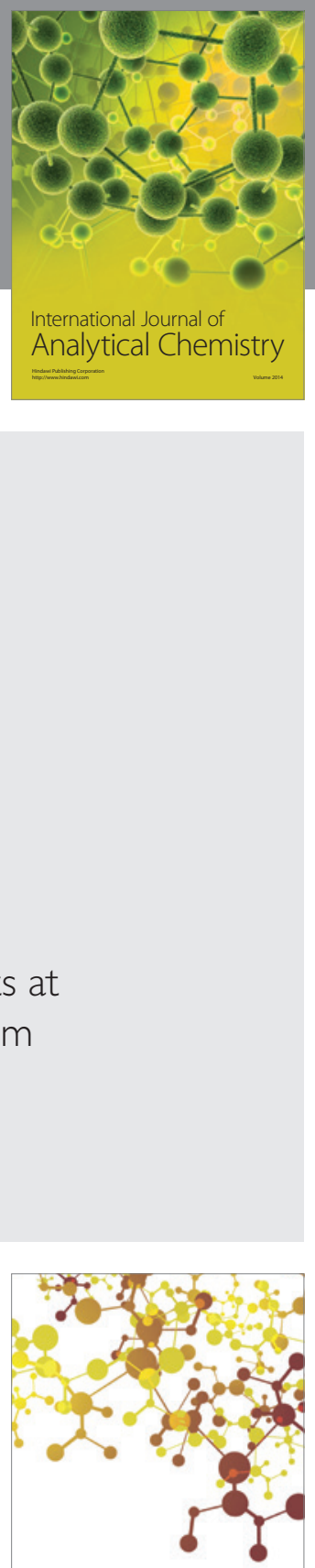

Journal of

Applied Chemistry
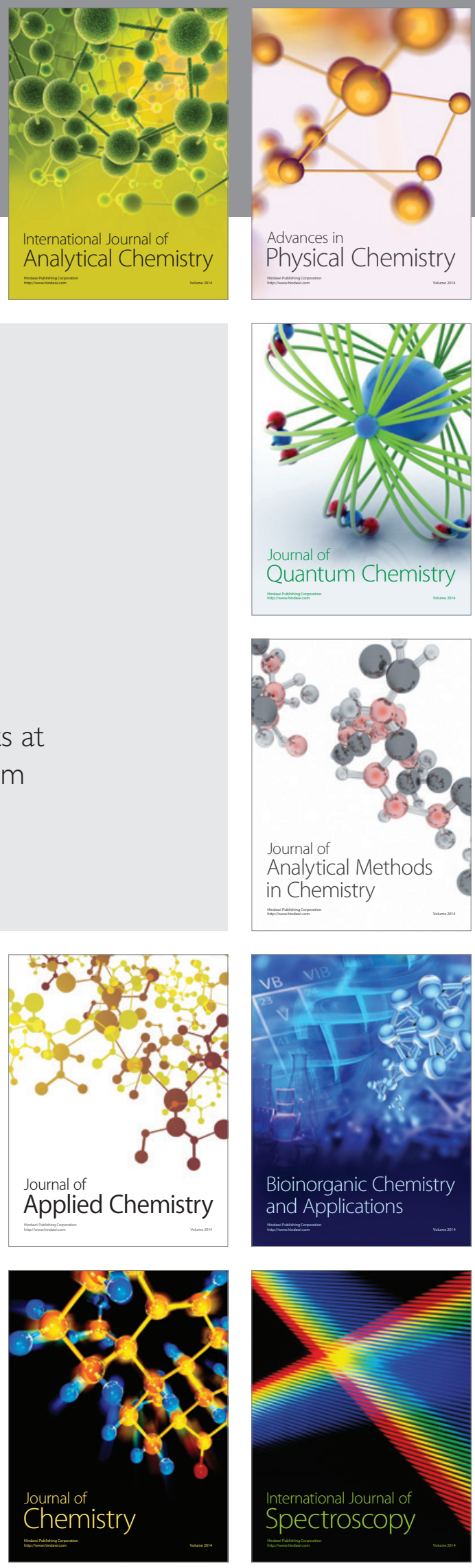